\title{
Computational Analysis on Numerical Simulation of Internal Flow Physics for Pump as Turbine in Renewable Small Hydro Energy Generation
}

\author{
Du Jianguo ${ }^{(D)},{ }^{1}$ Daniel Adu $\left(\mathbb{D},{ }^{1,2}\right.$ Emmanuel Acheaw, ${ }^{2}$ Shakir Hafeez, ${ }^{3}$ and Eric Ofosu Antw ${ }^{2}$ \\ ${ }^{1}$ School of Management Science \& Engineering, Jiangsu University, Zhenjiang 212013, China \\ ${ }^{2}$ Department of Energy and Environmental Engineering University of Energy and Natural Resources Sunyani, Sunyani, Ghana \\ ${ }^{3}$ Department of Management Sciences, COMSATS University Islamabad, Abbottabad Campus, Abbottabad, \\ Khyber-Pakhtunkhwa, Pakistan
}

Correspondence should be addressed to Daniel Adu; adudaniel39@yahoo.com

Received 27 August 2020; Revised 5 October 2020; Accepted 12 October 2020; Published 20 November 2020

Academic Editor: Mostafa M. A. Khater

Copyright (c) $2020 \mathrm{Du}$ Jianguo et al. This is an open access article distributed under the Creative Commons Attribution License, which permits unrestricted use, distribution, and reproduction in any medium, provided the original work is properly cited.

\begin{abstract}
Energy contributes significantly in almost all aspects of human life as well as economic activities and plays a crucial role in the infrastructural development of a county to alleviate poverty. Generating energy from a renewable source such as small hydropower through the application of pump operating as a turbine mode called Pump as Turbine is one of the best alternatives to provide clean and inexpensive energy. Using Pump as Turbine helps in generating reasonably priced hydroelectric power for communities in underdeveloped counties. This study investigates the effects of internal flow behaviour and performance of Pump as Turbine under different rotational speed and flow rate. The rotational speed is an essential physical parameter as it affects the Pump as Turbine operation. A model-specific speed centrifugal pump model with head $32(\mathrm{~m})$, flow rate of $12.5\left(\mathrm{~m}^{3} / \mathrm{h}\right)$ and the rotational speed of $2900 \mathrm{rpm}$, has been selected for the study. Numerical simulations have been conducted using the k- $\omega$ turbulence model to solve three-dimensional (3D) equations. The pump mode experimental data were used to confirm the results for better analysis. The results predicted that vortex and turbulent kinetic energy increase per rotational speed increase. Also, at the higher rotational speed, very high recirculation of flow is detected at the blade suction chamber, although the pressure side has a smooth flow. This study provides beneficial information which will serve as a reference to help improve PAT performance along with selecting PAT for a small hydropower site. Future works will consider the impact of blade thickness and cavitation in Pump as Turbine.
\end{abstract}

\section{Introduction}

Natural energy resources such as small hydropower have in recent times contributing significantly to a larger piece of the national energy resource types. Generating energy from nonrenewable sources is very familiar but is mostly through the use of expensive conventional hydro turbine $[1,2]$. As a result, they are using Pump as Turbine (PAT) for energy generation which can contribute significantly in stabilising electric power system to elevate the usage of other renewable sources such as thermal power plants which are rapidly depleting the environment. Electricity supply globally contributes about 20,053 terawatt-hours of installed energy, with about $16 \%$ of hydropower in many significant countries' electricity supply [3]. One of the challenges faced by hydraulic machinery is the movement of fluid flows as a result of the random vortex tube. Several studies have been conducted on various areas of pump to locate the vortex formation and its structure by [4-6]. Investigative terminologies were derived to obtain the velocity values. Studies to reduce pump systems operation caused by the undesirable effect of the air that enters the rotor pumps associated with the inundated vortex has also been carried out by $[7,8]$. Flow instabilities indirectly bring about some changes in parameter-related facilities. On the subject of investigating the vortices and turbulent kinetic energy as well as other flow 
physics of PAT, numerical CFD codes have been adopted for these studies. To verify the method applicability, computational fluid dynamics process was adopted as reported by $[4,9]$, in designing a pump station in place of the expensive experimental technique. Several technical solutions have been identified for antivortex effect [10-12]. Currently, there is the existence of diverse approaches to decrease vortex flow intensity in the suction chambers of centrifugal pumps. These approaches help to minimise the accumulated air caused by the vortex, which enters the pump as discussed by $[13,14]$. A lot of researches have been conducted on PAT since 1930 [15], using diverse types of pumps and the results show that PAT could stand selected as a perfect choice for hydro energy production considering its good benefits [16-18]. The advantages of using PAT in preference to small hydropower turbines were outlined by [19].

Similarly, according to [20], PAT could potentially be used to recover the hydraulic energy dissipated in the hydro turbines network. Choosing a commercial pump for PAT has not always been an easy task since manufacturers of pump have not provided PAT performance conditions [21]. Hence, a recent study on PAT has been dependent on the development of inverse process prediction of centrifugal pumps. Fernandez [22] described the behaviour of a PAT through an experiment. Studies were conducted by [23-25] to determine how PAT efficiency at the best efficiency point (BEP) could be achieved. It is necessary to conduct this study to analyse the internal flow physics of PAT to provide useful information for PAT selection in hydraulic power sites and also serve as a reference for further research. Ren and Wang [26] conducted research on adaptation for optimisation and control of complex renewable energy systems. Dang and Du [27] conducted a study on synchronisation-based guaranteed-performance formation design for swarm systems, and the results revealed that as a synchronisation-based guaranteed-performance formation is attained, the centre of forming the entire swarm system could become immobile. Zhang et al. [28] carried out a study on an innovative aerial manipulator with tandem ducted fans: modeling, control, and simulation and they observed that a projected composite adaptive controller could enable an aerial vehicle to attain good performance in manipulator motion. Other researchers also considered simulation and power system analysis in their studies.

\section{Simulation Setup}

2.1. Unsteady Simulation Setup and Methodology. As the numerical calculation is vital for computational analysis, setup was done using ANSYS CFX code 17.0 in this study to explain the RANS flow equations in a specific pump model. Outcomes from study simulation gave a general idea of the pump flow characteristics. The steady results were therefore used to initiate the unsteady simulation conditions. As turbulence models are essential in simulation, the shear stress transport (SST $k$ - $\omega$ ) turbulence model was selected for the unsteady numerical simulation. This model came from the k- $\omega$ and $k-\square$ turbulence models. As it could mechanically change between the adjacent wall boundary and actual flow [29], this $k$-omega $(k-\omega)$ model has a twoequation computational turbulence model which helps in explaining RANS equations. It is useful for predicting turbulence when two partial differential equations are involved for two variables, for example, $k$ and $\omega$, where $k$ represents the kinetic energy and $\omega$ represents the dissipation of actual rate.

$$
\begin{aligned}
\frac{\partial(\rho k)}{\partial t}+\underbrace{\frac{\partial}{\partial x_{i}}(\rho \bar{\mu} i \kappa)}_{I I}= & \underbrace{\frac{\partial}{\partial x_{i}}\left[\left(\mu+\frac{\mu_{T}}{\sigma_{\kappa}}\right) \nabla \kappa\right]}_{I I I}+\underbrace{P \kappa}_{I V}-\underbrace{\beta * \rho \kappa \omega}_{V}, \\
P_{\kappa} & =\left(2 \mu_{T} \frac{\partial \bar{\mu}_{i}}{\partial x_{j}}-\frac{\partial \bar{\mu}_{i}}{\partial x_{j}}-\frac{2}{3} \rho \kappa \frac{\partial \bar{\mu}_{i}}{\partial x_{j}} \delta_{i j}\right),
\end{aligned}
$$

where $\sigma_{\kappa}$ and $\beta^{*}$ are the equation constants [14].

$$
\begin{aligned}
\frac{\partial \rho \omega}{\underbrace{\partial t}_{I}}+\underbrace{\frac{\partial}{\partial x_{i}}(\rho \bar{\mu} i \omega)=}_{I I} & \underbrace{\frac{\partial}{\partial X_{i}}\left[\left(\mu+\frac{\mu_{T}}{\sigma_{\omega, 1}}\right) \nabla \omega\right]}_{I I I} \\
& +\underbrace{\gamma 2\left(2 \rho \frac{\partial \bar{\mu}_{i}}{\partial x_{j}}-\frac{\partial \bar{\mu}_{i}}{\partial x_{j}}-\frac{2}{3} \rho \omega \frac{\partial \bar{\mu}_{i}}{\partial x_{j}} \delta_{i j}\right)}_{I V} \\
& -\underbrace{-\beta_{2} \rho \omega^{2}+\underbrace{2 \frac{\rho}{\sigma_{\omega, 2} \omega}-\frac{\partial \kappa}{\partial x_{\kappa}}-\frac{\partial \omega}{\partial x_{\kappa}}}}_{V I} .
\end{aligned}
$$

The advection scheme was set to high resolution, and fluid selected was ideal water at $25^{\circ} \mathrm{C}$. All the wall surface roughness within the control volume was set to $50 \mu \mathrm{m}$. The inlet and outlet boundary conditions remained with a static pressure of $1 \mathrm{~atm}$ at inlet and mass flow rate at the outlet. The impeller was set to rotate at a time step of $0.0002222 \mathrm{~s}$ which represents $2^{\circ}$. The impeller was formed to revolve for 12 times with a total time of $0.48 \mathrm{~s}$. Thus, 2150 inconsistent results were obtained for the entire numerical simulations. The convergence control was set as 10 all-out coefficient loops with a convergence criterion of $10^{-6}$ in each time step to achieve a periodic flow. By changing the mass flow level, performance curves of both pump PAT modes were attained. A 5\% medium turbulence intensity for the inlet conditions was considered. The inlet and outlet pipes were set in a stationary frame, and the impeller was placed in a rotating frame. The interfaces between rotary and fixed components were assigned to a general grid and rotor-stator interface, respectively [30]. Figures 1 and 2 show the flow chart of the simulation process and simulation tool screenshots, respectively.

2.2. Generated Mesh Domains. The summary of the created meshes is shown in Figure 3. The whole computational field of the selected centrifugal pump for modelling is divided into six parts, namely, suction pipe, wear ring, front chamber, back chamber, impeller, and volute. The hybrid meshes are generated with the mesh generation tool called ANSYS-ICEM 17. On account of the complex structure of the impeller, the mesh was generated via tetrahedron 


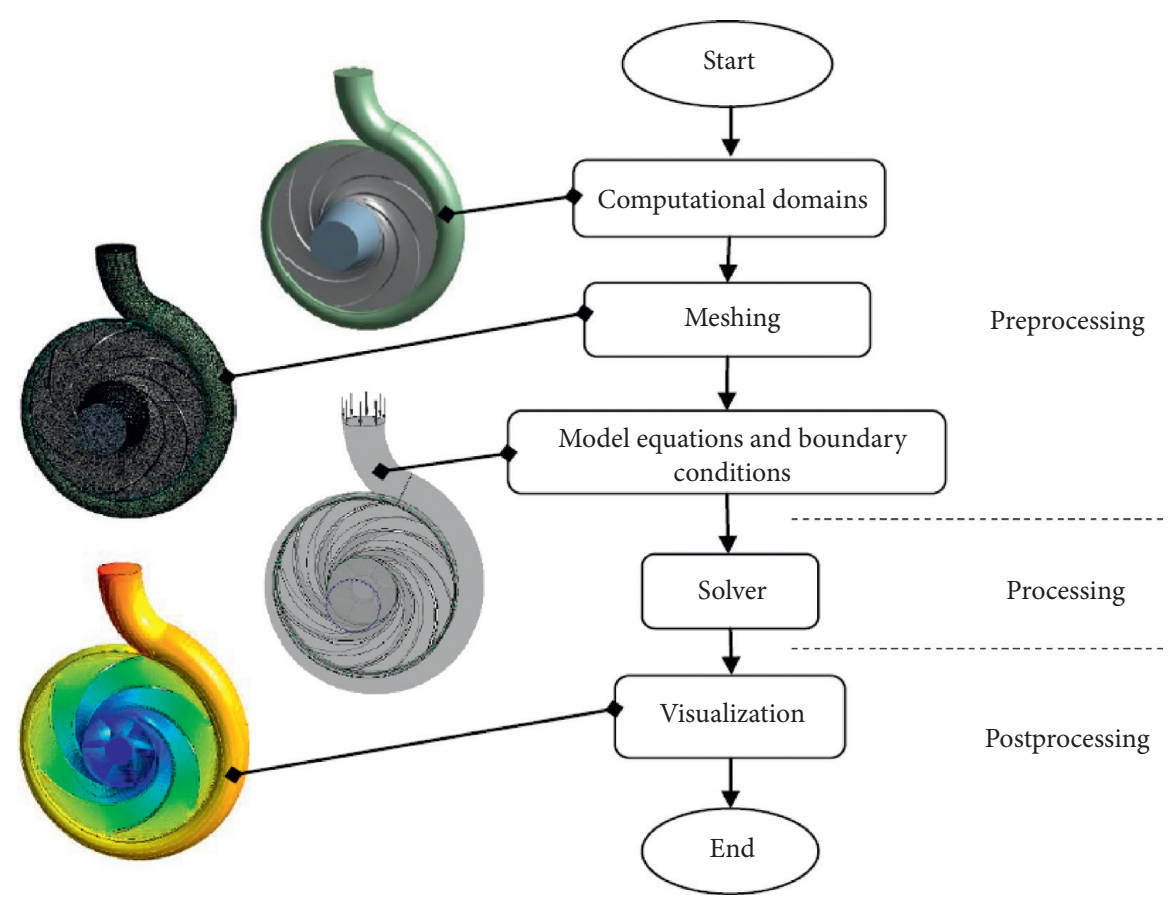

FIGURE 1: Flow chart of the simulation process.
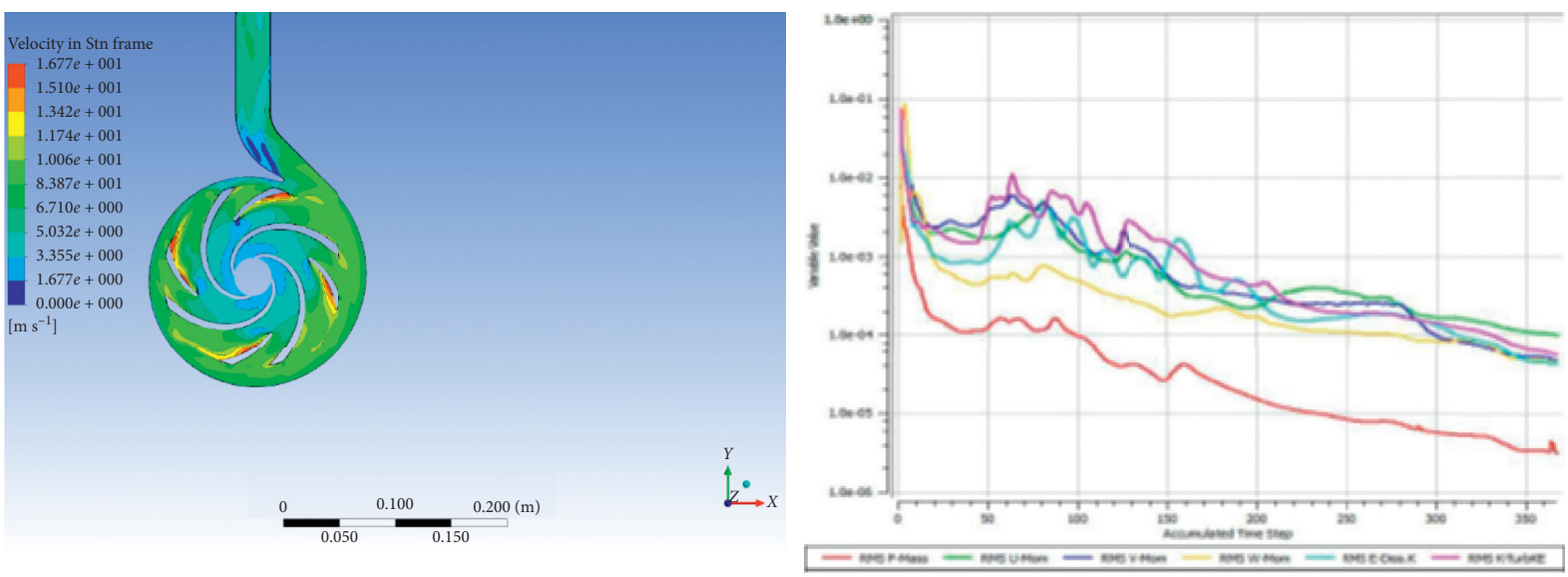

Figure 2: Simulation tool screenshots.

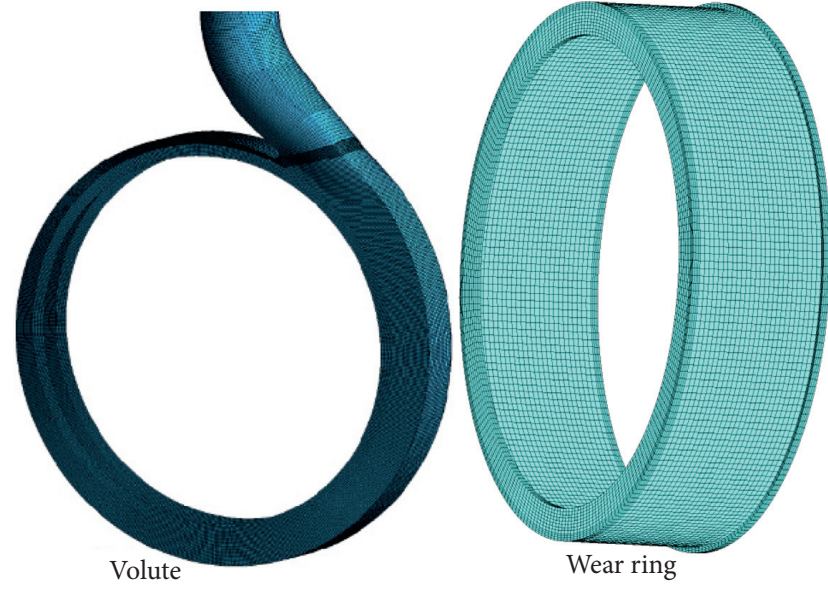

Figure 3: A generated mesh of selected flow domain.
TABLE 1: Operational and geometric parameters of the selected centrifugal pump model.

\begin{tabular}{lcc}
\hline Parameter & Symbol & Value \\
\hline Flow rate & $Q_{d}$ & $12.5 \mathrm{~m}^{3} / \mathrm{h}$ \\
Efficiency & $\eta$ & $56 \%$ \\
Specific speed & $n s$ & 47 \\
Rotational speed & $n$ & $2900 \mathrm{rpm}$ \\
Inlet diameter of impeller & $D i$ & $104 \mathrm{~mm}$ \\
Outlet impeller diameter & $D 2$ & $160 \mathrm{~mm}$ \\
Splitter blades inlet diameter & $\beta 1$ & 106 \\
Base circle of volute diameter & $D 3$ & $170 \mathrm{~mm}$ \\
Inlet diameter of volute & $D 4$ & $174 \mathrm{~mm}$ \\
Inlet width & $b 3$ & $18 \mathrm{~mm}$ \\
Offset angle of splitter blade & $\theta$ & 5 \\
\hline
\end{tabular}



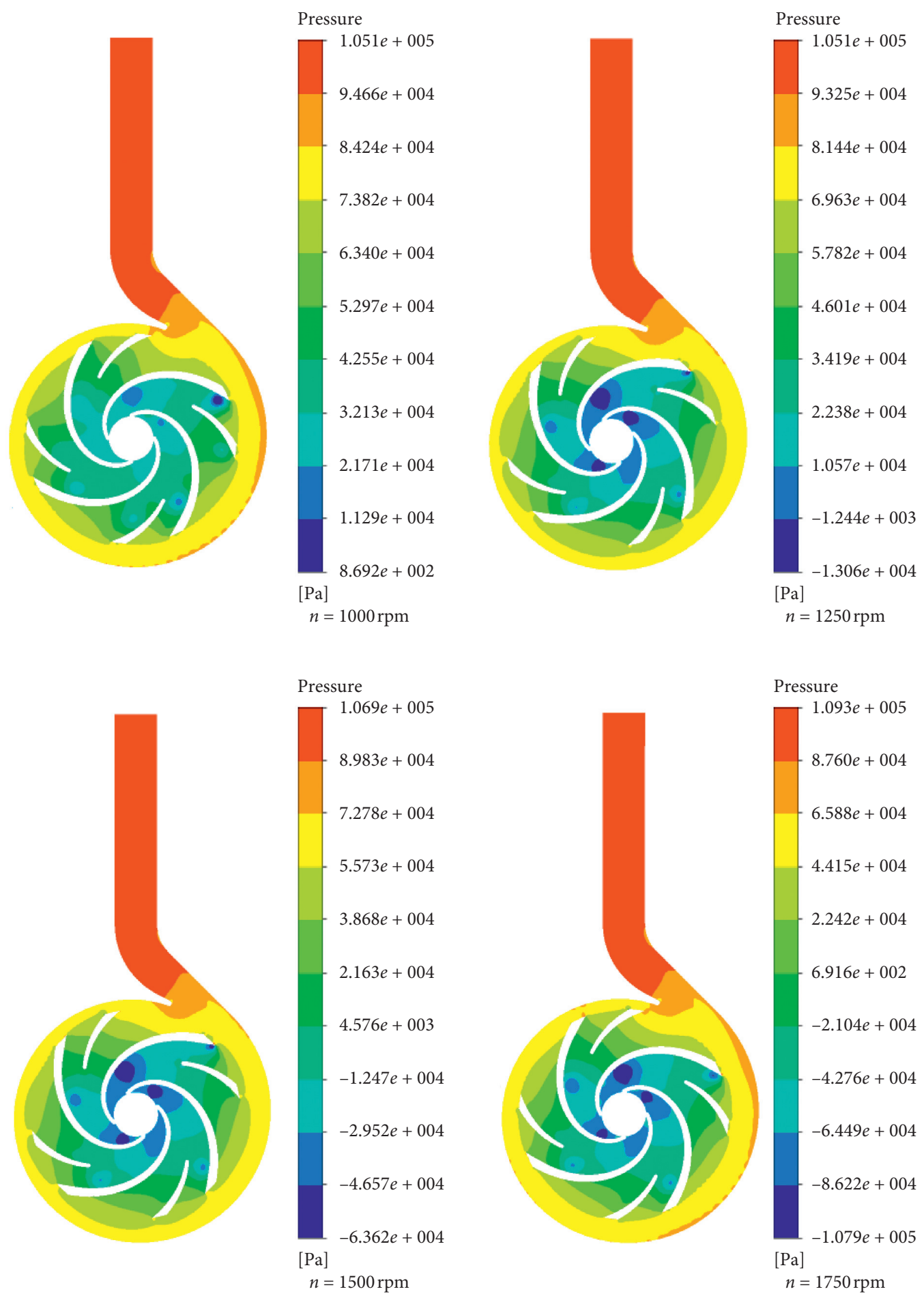

FIgURE 4: 3D pressure distribution of the centrifugal PAT model at BEP.

unstructured mesh, as hexahedron structured mesh was likewise generated for the other components. The mesh was polished to include the detail flow structures both at the blade surface and tongue areas, as stated by [31].

2.3. Centrifugal Pump Model. A selected centrifugal pump with four main blades and splitter blades to provide a head $H_{d}$ of $12 \mathrm{~m}$, flow rate $Q_{d} 12.5\left(\mathrm{~m}^{3} / \mathrm{h}\right)$ and rotational speed $n=2900(\mathrm{r} / \mathrm{min})$, was selected for this study to operate in reverse mode as turbine (PAT). The pump is mainly composed of long straight pipes, an outlet impeller with width of $6(\mathrm{~mm})$, and blade outlet with angle of $30^{\circ}$. The entire computational flow domains were generated using a three-dimensional (3D) Pro/E 5.0 software. The whole design geometric plus operational parameters of the carefully chosen pump model under study are shown in Table 1. 

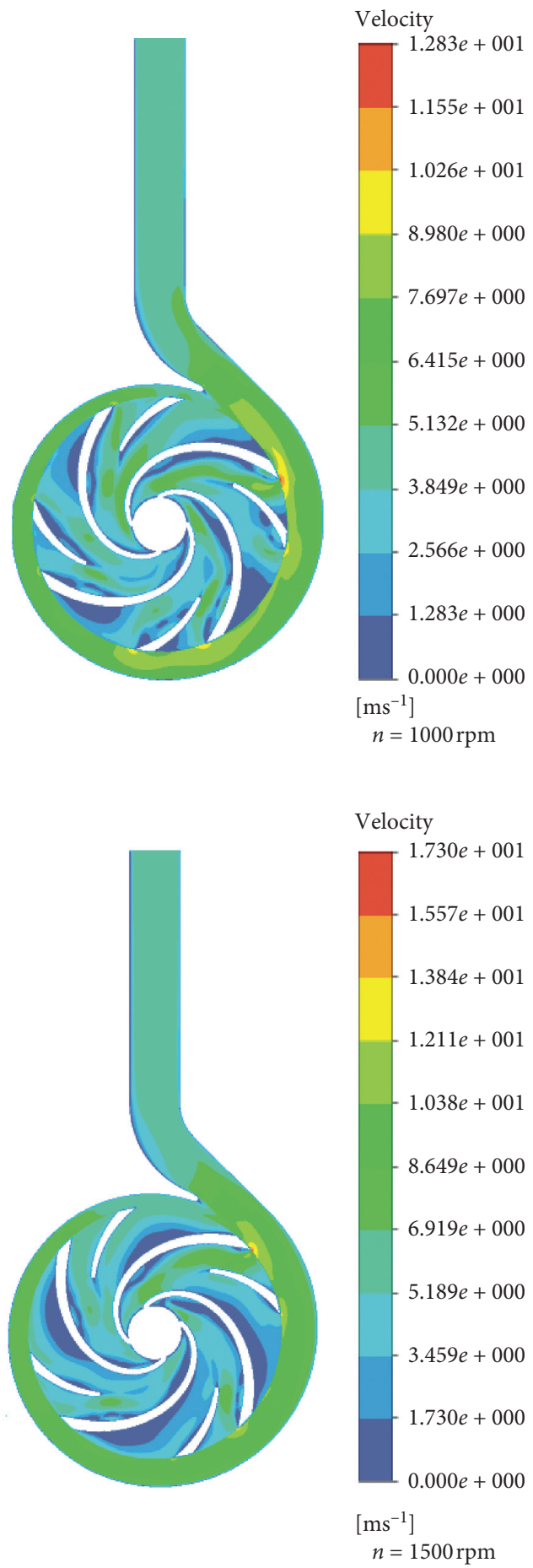
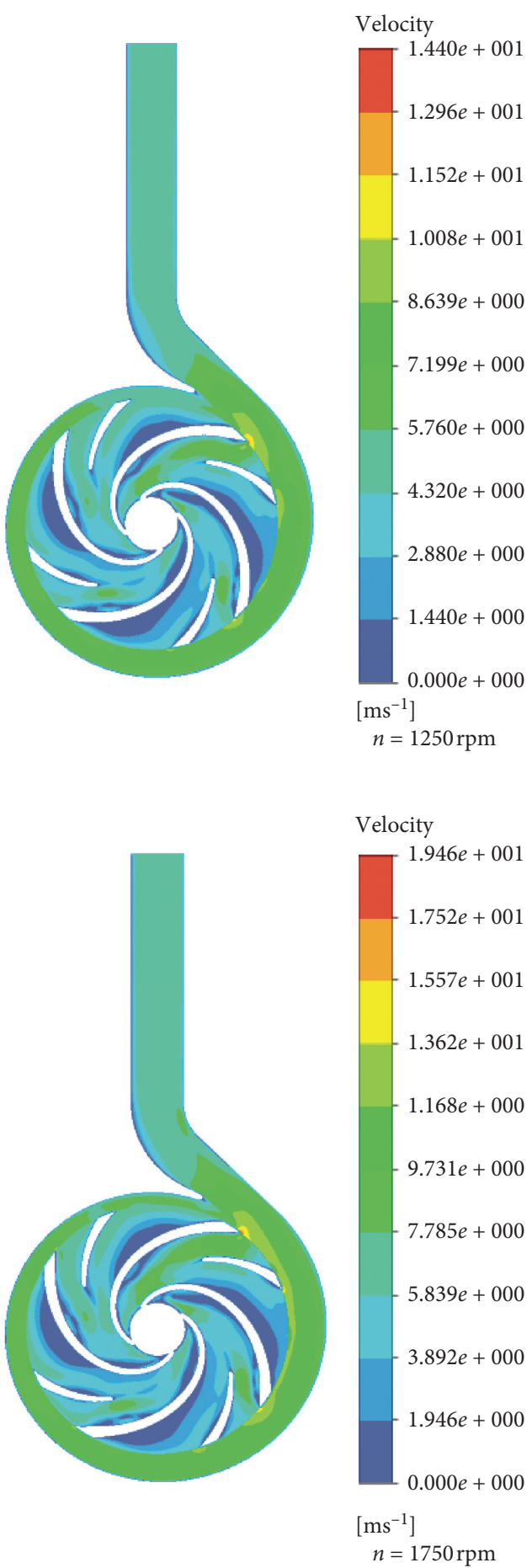

FIgURE 5: 3D velocity distribution of the selected centrifugal PAT model in diverse speed at BEP.

\section{Results and Discussions}

3.1. Pressure Distribution of PAT. The characteristics of a 3D pressure distribution of PAT under different speed conditions at the BEP have been discussed. The difference in rotational speed pattern with the change in rotational speed results are shown in Figure 4. The results reveal that, as the rotational speed increases along with the fluid flow within the domains, pressure decreased from the leading edge to the trailing edge of the PAT impeller. A high-pressure region is observed at inlet pipe opening of the PAT. As water moves inside the suction pipe through the stream channel of the impeller, the pressure decreases as a result of an increase in velocity through a gradual reduction of the cross-sectional area of the volute casing.

Furthermore, the static pressure decreases continuously along the impeller flow passage beginning at the suction side to the pressure side and then to the outer of the impeller as 

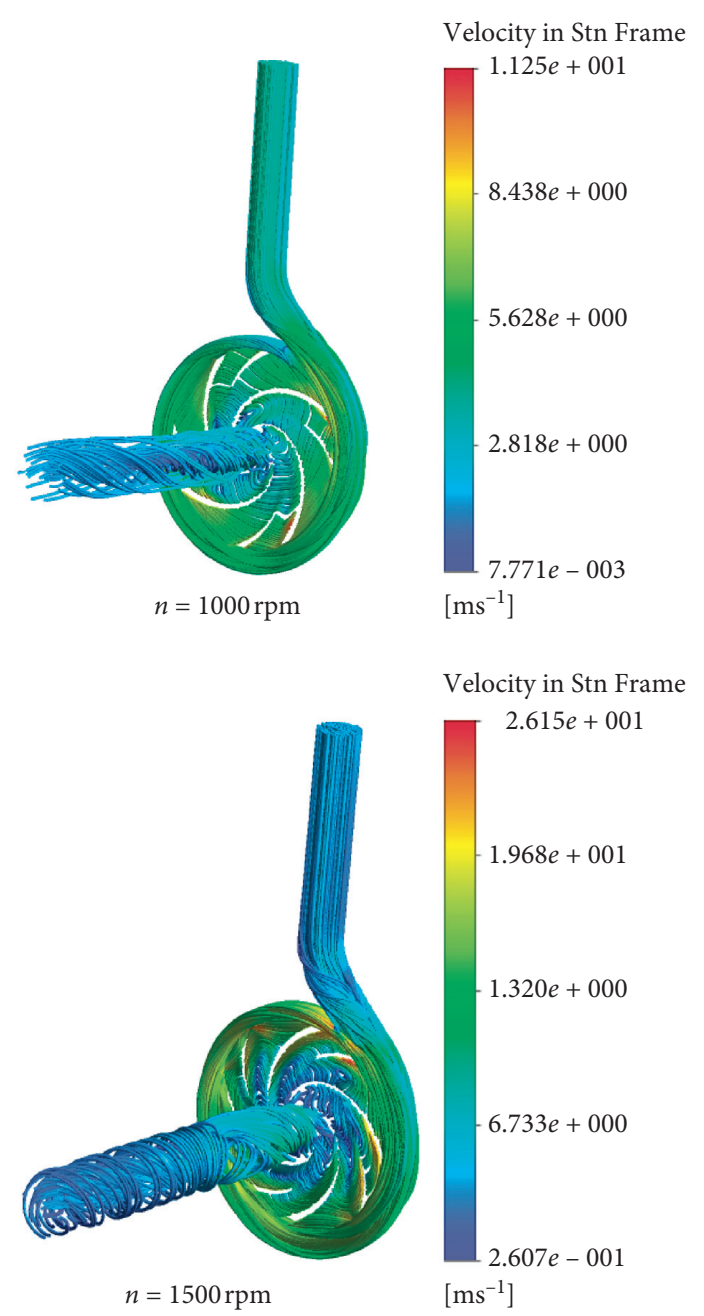
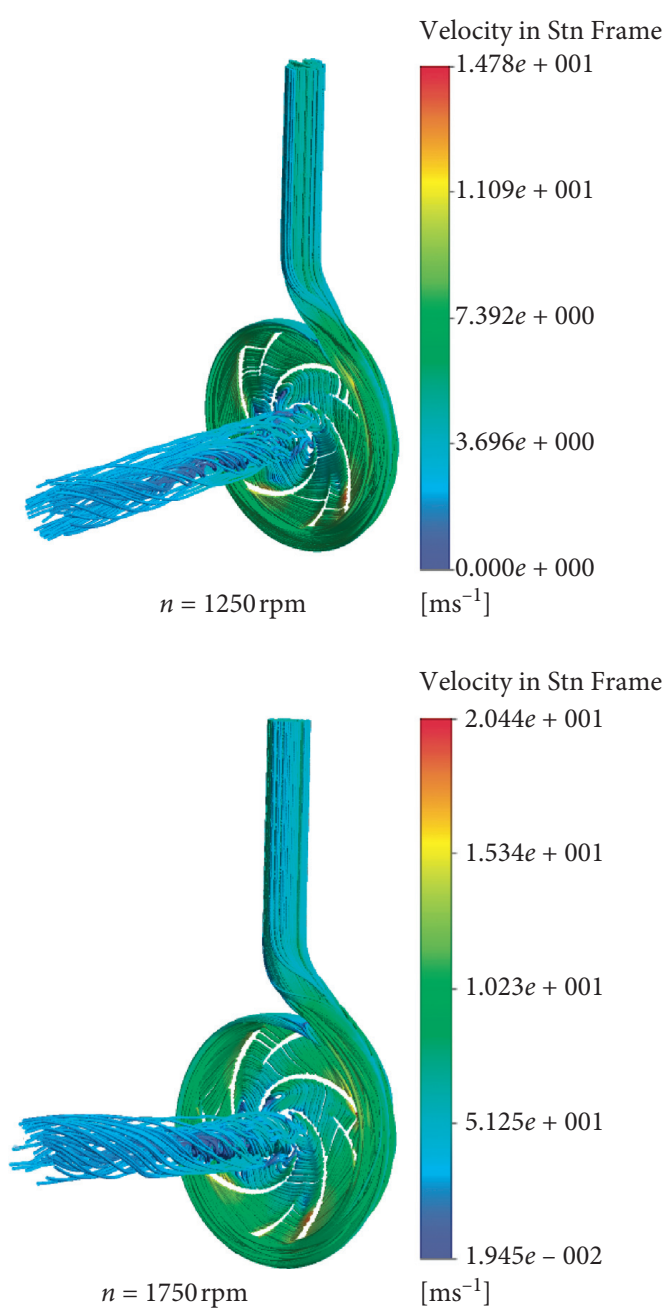

Figure 6: 3D streamline plots coloured by relative velocity for the selected PAT model at $Q=12.5\left(\mathrm{~m}^{3} / \mathrm{h}\right)$.

energy was transmitted to the blades. It was comparing the performance of the four rotational conditions such as $1000 \mathrm{rpm}, 1250 \mathrm{rpm}, 1500 \mathrm{rpm}$, and $1750 \mathrm{rpm}$, respectively. It can be observed that the increase in rotational speed decreases the pressure along the impeller region. Besides, the pressure drops closer to the exit duct of the suction pipe increases. At the maximum rotational speed, very high recirculation of flow in the blade the suction side has taken place, although the pressure side has a smooth flow. Again, as the rotational speed increases, flow pattern at the trailing edge of the impeller occurs, resulting in the continuous fluid movement. Minimal pressure is then observed in the suction side of the impeller per an increase in rotational speed.

\subsection{Velocity Distribution in the PAT Model. Figure 5 shows} the PAT velocity distribution from the different rotational speed at the BEP. It is observed that velocity increases as the cross-sectional area of the volute decreases due to the reduction of transversal size. The fluid moves smoothly through the suction pipe at a nominal speed. It also revealed that the velocity of the fluid slowed down after it reached the trailing edge along the volute after which rate of the fluid tended to increase slightly once again. The maximum rate is located inside the volute with a minimum velocity at the side of the impeller. As the rotational speed increases, velocity decreases. As the flow reaches the volute tongue region, velocity increases, but the velocity decreases as the rotational speed increases. Inside the impeller passage, weak velocity ranging from 0 to $2.9 \mathrm{~m} / \mathrm{h}$ was observed and also the trailing edge of the blades was characterised with a higher rate. This effect could be as a result of the direction of the flow devoid of guide vane into the outlet. As the rotational speed increases to $n=1750 \mathrm{rpm}$, the average velocity distribution in the flow passage decreases at all operating conditions. In general, the intensity of the velocity flow in the volute is higher than the impeller in all operating conditions as well as at rotational speed $n=1000 \mathrm{rpm}$ to $1750 \mathrm{rpm}$ for the reason that the fluid energy was extracted by the movement of the impeller in the counterclockwise direction.

3.3. Relative Velocity Analysis for PAT. Relative velocity distribution of PAT in a streamwise direction of a selected PAT model is shown in Figure 6. The velocity increases as the fluid flow along with PAT impeller passage, as shown in 


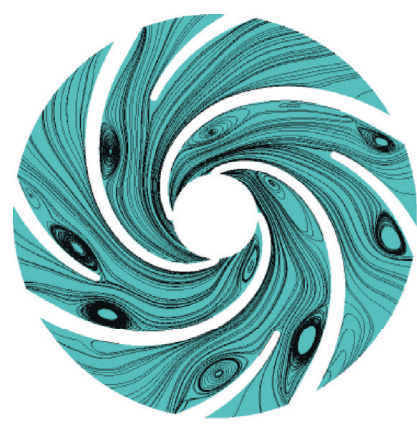

$n=1000 \mathrm{rpm}$

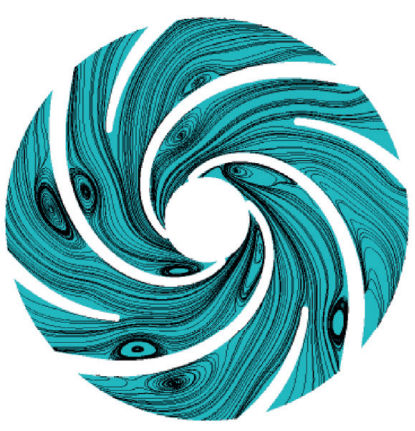

$n=1250 \mathrm{rpm}$

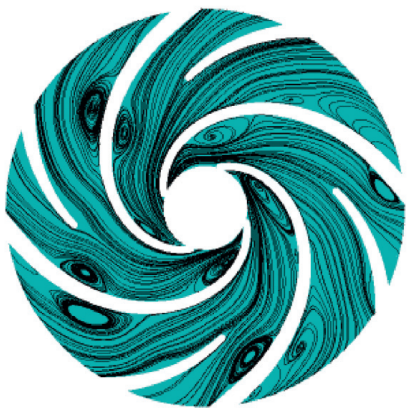

$n=1500 \mathrm{rpm}$

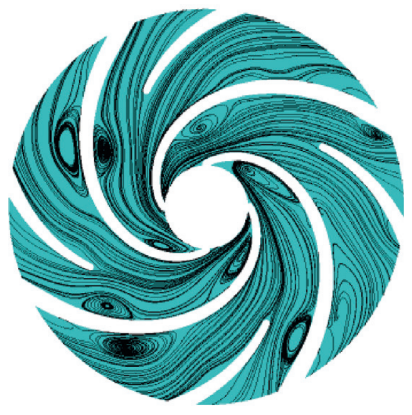

$n=1750 \mathrm{rpm}$

(a)

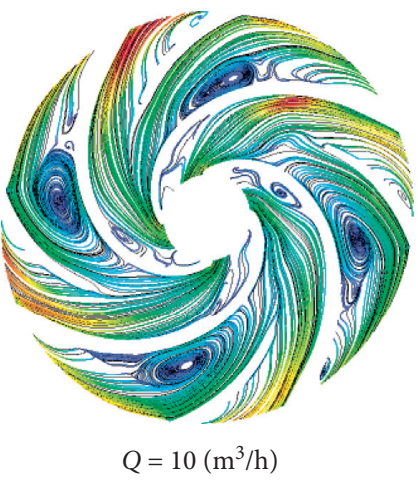

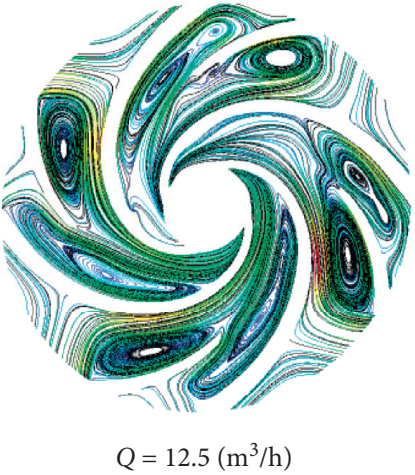

(b)

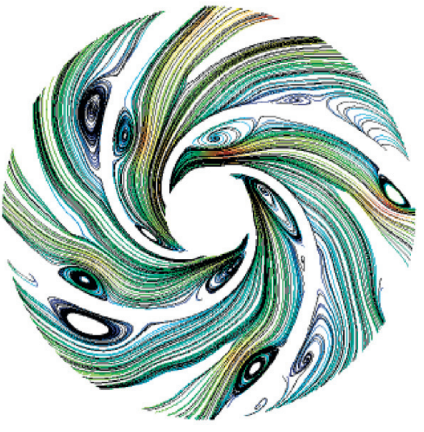

$Q=15\left(\mathrm{~m}^{3} / \mathrm{h}\right)$

Figure 7: (a) Streamline vortex dissemination for Pump as Turbine at different speed level at BEP. (b) Streamline vortex dissemination for Pump as Turbine at different flow rate $n=1500 \mathrm{rpm}$.

Figure 6. Velocity increases gradually as the flow moves along the leading edge through the trailing edge with a higher relative rate located at the volute tongue and trailing edge. Minimum absolute rate is found at the discharge with the discharge pipe recording the lowest rate. For better understanding and more precise visualisation of fluid movement along the impeller passage, the relative velocity distribution of different rotational speed at $Q=12 \mathrm{~m}^{3} / \mathrm{h}$ is used. It can be observed that as the fluid moves within the flow passage along with the rotation of the impeller, the relative velocity uninterruptedly increases. As rotational speed increases, relative velocity also increases with the highest velocity recorded at $n=1500 \mathrm{rpm}$. As the flow moves out of the discharge smoothly through the discharge pipe along with the volute casing, absolute rate progressively decreases, as shown in Figure 6.

3.4. PAT Flow Instabilities Analysis. The vortex and turbulent flow distribution of a selected centrifugal pump model to operate as PAT under different speeds at best efficient point (BEP) are shown in Figure 7. Considering the various rotational speeds operation, vortex happened at the various rotational speeds with the higher number of vortex was observed to be more assertive at $n=1500 \mathrm{rpm}$. However, the interaction of vortex at this rotational speed is weak. As the rotational speed increase, vortex also increases, demonstrating that the rotation of the PAT has a positive effect on the vortex increase (Figure 7(a)).
Similarly, the vortex increases with an increase in flow rate as can be seen in Figure 7(b). The maximum vortex is found on the suction side, whereas the pressure side records the minimum vortex (Figure 7(a)). It can be seen from these figures that the fluid flow area of the impeller passage $n=1500$ has the maximum vortex. Nevertheless, a minimal vortex is located along the pressure side of the impeller at each operating condition. On the contrary, the suction side contains higher vortex than the trailing edge at each rotational speed, as can be seen in Figure 7(b). It is observed that as the speed increases, vortex within the suction chamber increases, whereas the vortex along the pressure side of the impeller passage disappears. The flow around the turbine's no-load performance becomes so complex that the flow in the recirculation zone becomes highest, creating vortices in all parts of the machine. Then, the flow becomes unstable. The recirculation zone accrues and melts, and then the vortex flow is washed away. Complex unsteady turbulent flow existence in PAT discloses the occurrence a more significant impact of vortex flow pattern. Maximum turbulence is located around trailing edge next to leading edge with lower turbulence located at the suction side [32-37]. As rotational speed increases, turbulence increases as well. Similarly, an increase in fluid flow from the suction side through leading edge increases the turbulent flow energy, as shown in Figure 8. At rotational speed $n=1000 \mathrm{rpm}$, no vortex was recorded at the suction side. 

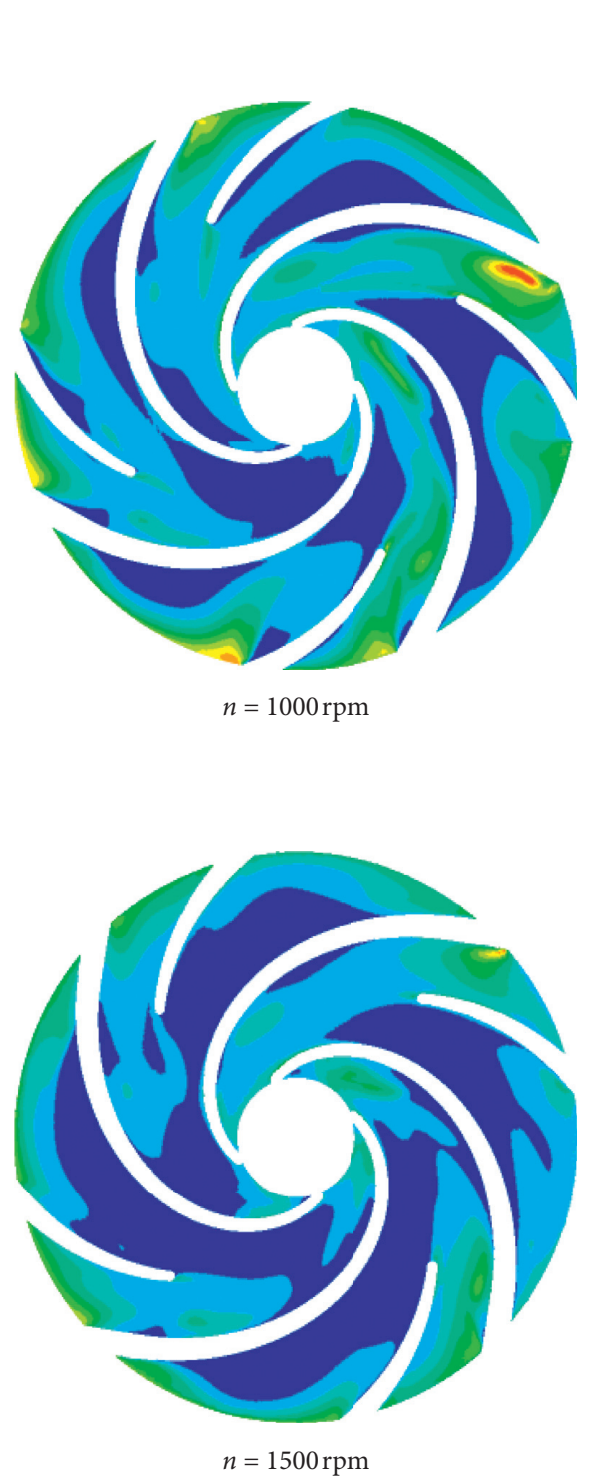

Turbulent kinetic energy

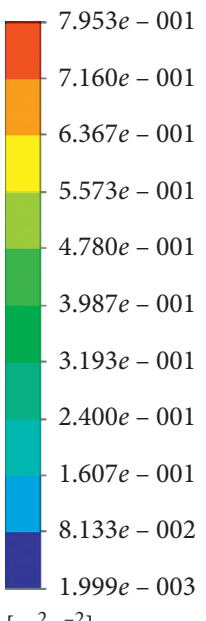
$\left[\mathrm{m}^{2} \mathrm{~s}^{-2}\right]$

Turbulent kinetic energy

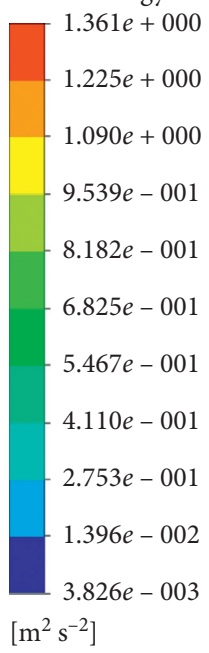

Turbulent kinetic energy

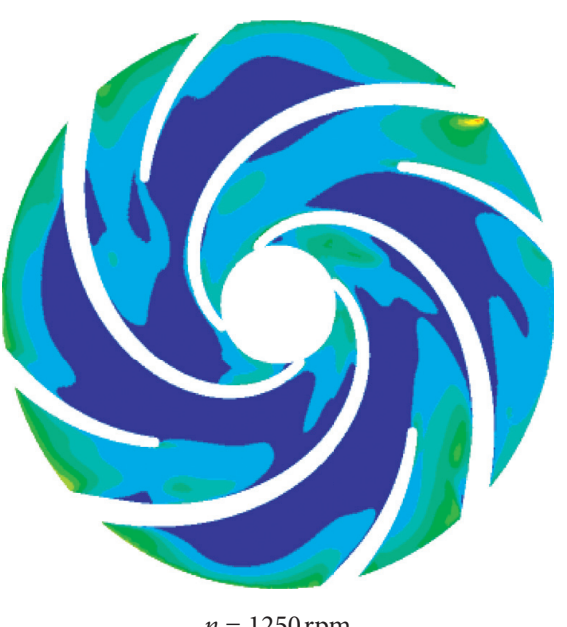

$9.465 e-001$
$8.520 e-001$
$7.579 e-001$
$6.632 e-001$
$5.688 e-001$
$4.744 e-001$
$3.799 e-001$
$2.855 e-001$
$1.911 e-001$
$9.667 e-002$
$2.249 e-003$ $\left[\mathrm{m}^{2} \mathrm{~s}^{-2}\right]$

Turbulent kinetic energy

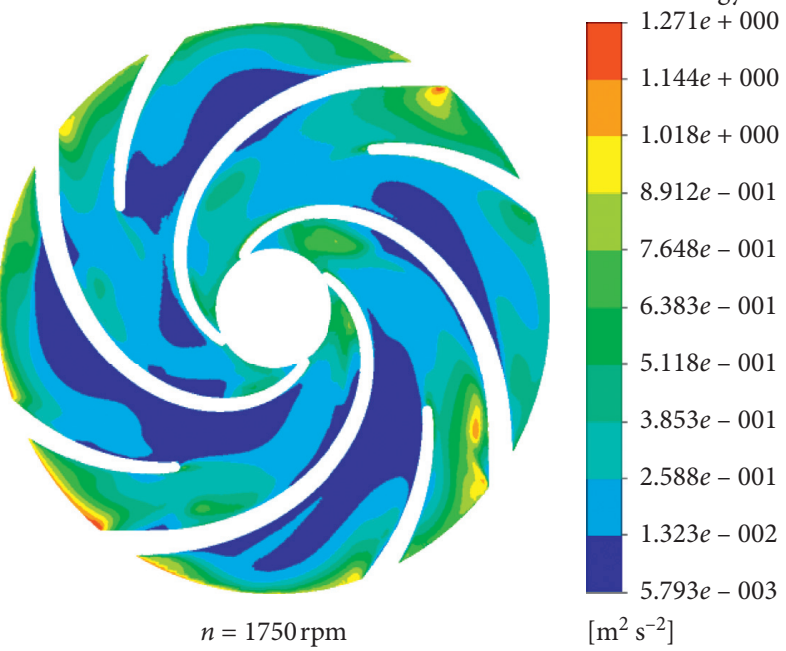

Figure 8: Turbulence dissemination for the Pump as Turbine diverse speed at BEP.

\section{Conclusions}

A full CFD unsteady numerical simulation has been carried out on a selected PAT model to analyse the vortex behaviour, turbulent kinetic energy, pressure, and velocity distribution in PAT. Vortices and turbulent kinetic energy influences on the internal flow physics of PAT have been investigated considering the variation of rotational speeds and flow rate. The results revealed that flow unsteadiness and partial flow structure occurred. Again, vortices are formed at relatively higher rotational speed and flow rate. Moreover, vortices were also formed on blade pressure side at a lower rotational speed. The turbulent kinetic energy increases as speed increases. Also, the pressure and velocity distributions at the inlet are higher at all operating conditions than the outlet because the fluid energy at high elevation is extracted in the PAT mode. In the velocity streamline distribution, fluid moves within the flow passage along with the rotation of the impeller, and the relative velocity uninterruptedly increases. Minimum relative velocity is found at the discharge with the discharge pipe recording the lowest velocity vortices. This has revealed other areas that need to be looked at thoroughly in future works which include the cost analysis of PAT and impact of blade thickness in Pump as Turbine. The study serves as a reference to provide valuable data to improve PAT performance in conjunction with selecting PAT for small hydropower generation. The study has some limitations such as obtaining needed data for the research which was a challenge since a lot of people rely on the same work station for their works. Some relevant information about the study was not accessible to acquire.

\section{Data Availability}

Data supporting the findings of this study are available from the corresponding author $(\mathrm{AD})$ on request. 


\section{Conflicts of Interest}

The authors declare that they have no conflicts of interest.

\section{Acknowledgments}

The authors would like to thank Mrs. Joyce Adu, Nana AduKumi, and Dr. Muhammad Aamir Shafique Khan, for their proofreading and correction, and The Special Funds of the National Social Science Fund of China, for their financial support, with grant no. 18VSJ038 as well as National Science Foundation of China under grants 71974081, 71704066, and 71971100, for supporting this work.

\section{References}

[1] A. Daniel and Z. Jinfeng, "Case study of status and potential of small hydropower plants in southern African development community," Energy Procedia, vol. 141, pp. 352-359, 2017.

[2] Z. Jinfeng and A Daniel, "Review on China's renewable energy and future projections," International Journal of Smart Grid and Clean Energy, vol. 7, 2018.

[3] S. V. Jain and R. N. Patel, "Investigations on pump running in turbine mode: a review of the state-of-the-art," Renewable and Sustainable Energy Reviews, vol. 30, pp. 841-868, 2014.

[4] H.-X. Chen and J.-H. Guo, "Numerical simulation of 3-D turbulent flow in the multi-intakes sump of the pump station," Journal of Hydrodynamics, vol. 19, no. 1, pp. 42-47, 2007.

[5] A. Daniel and Z. Jinfeng, "The prospects \& submissions for small hydropower development in sub-saharan african," in Proceedings of the IOP Conference Series: Earth and Environmental Science, 2020, Zhengzhou, Chin, June 2018.

[6] L. Hai-feng, C. Hong-xun, M. Zheng, and Y. Zhou, "Experimental and Numerical Investigation on free Surface Velocity of vertical vortices at hydraulic intakes," Journal of Hydraulic Engineering, ASCE, vol. 120, no. 3, pp. 284-297, 1994.

[7] V. Iwano, T. Shibata, T. Nagahara, and T. Okamura, "Numerical prediction method of a submerged vortex and its application to the flow in pump sumps with and without a baffle plate," in Proceedings of the 9th International Symposium on Transport Phenomena and Dynamics of Rotating Machinery, Hawaii, HL, USA, April 2002.

[8] A. Young-Joon and B. R. Shin, "Numerical investigation of suction vortices behaviour in a centrifugal pump," Journal of Mechanical Science and Technology, vol. 25, no. 3, p. 767 77, 2011.

[9] T. Righetti, K. Kamemoto, and J. Matsui, "CFD prediction and model experiment on suction vortices in pump sump," in Proceedings of the 9Th Asian International Conference on Fluid Machinery, Jeju, Korea, September 2007.

[10] J. H. Ables, "Vortex problem at intake lower st. Anthony falls lock and dam Mississippi river, minneapolis, Minnesota, tech," US Army Corps of Engineers, Waterways Experiment Station, Vicksburg, MS, USA, 1979.

[11] D. Ispas, "Curgerea fluidului vascos in camerele de aspiratie ale pompelor centrifuge, Teza de doctorat," Institutul Politehnic Bucuresti, vol. 21, 1985.

[12] A. R. Kabiri-Samani and S. M. Borghei, Effects Of Anti-Vortex Plates On Air Entrainment By Free Vortex, Scientia Iranica Transactions A: Civil Engineering, Tehran, Iran, 2013.
[13] A. Ciocanea, "Determinarea volumului de aer din curgerile cu vartej in camerele de aspiratie," in Proceedings of the 2-nd Conference of Hydropower Engineering Dorin Pavel, Bucuresti, Romania, March 2002.

[14] K. Kamemoto, "On contribuiton of advanced vortex element methods toward virtual reality of unsteady vortical flows in the new generation of CFD," Journal of the Brasilian Society of Mechanical Science and Engineering, vol. 18, 2004.

[15] M. Rossi and M. Renzi, "Pump-as-Turbine for energy recovery applications: the case study of an aqueduct," Energy Procedia, vol. 101, pp. 1207-1214, 2016.

[16] D. Buono, A. Mazzone, U. Cesaro, and A. Senatore, "Study of a pump as turbine for a hydraulic urban network using a tridimensional CFD modeling methodology," Energy Procedia, vol. 82, pp. 201-208, 2015.

[17] Document of the world pumps website, Advantages of Using Pumps as Turbines, Water \& Wastewater, Applications, Elsevier, Amsterdam, Netherlands, 2013.

[18] J. Zhang, D. Adu, and Y. Fang, "The potential for small hydropower plants in Ghana," Innovative Energy \& Research, vol. 6, p. 166, 2017.

[19] T. Agarwal, "Review of pump as turbine (PAT) for microhydropower," International Journal of Emerging Technology and Advanced Engineering, vol. 2, no. 11, 2018.

[20] A. A. Williams, "Pumps as turbines for low cost micro hydro power," Renewable Energy, vol. 9, no. 1-4, pp. 1227-1234, 1996.

[21] S. L. Frosina, Fluid Mechanics and Thermodynamics of Turbo Machinery, 5th edition, Elsevier, 2005, https://www.google. com/search?rlz=1C1GCEU_enIN894IN894\&q=Amsterdam\&st ick=H4sIAAAAAAAAAOPgE-LUz9U3MDJLSYpXYgcxs40LtL Syk63084vSE_MyqxJLMvPzUDhWGamJKYWliUUlqUXFi1g 5HXOLgayUxNwdrIwA9iXLVlEAAAA\&sa=X\&ved=2ahUKEd wjhqbDJoLfsAhVBjOYKHU_AOAQmxMoATAZegQIJhAD.

[22] J. Fernandez, "Performance of a centrifugal pump running in inverse mode," Journal of Power and Energy, vol. 218, no. 4, 2004.

[23] R. Barrio, J. Fernandez, J. Par rondo, and E. Blanco, "performance prediction of a centrifugal pump working in direct and reverse mode using computational fluid dynamics," in Proceedings of the International Conference on Renewable Energies and Power Quality, pp. 1-5, Granada, Spain, June 2010.

[24] S. Rawal and J. T. Kshirsagar, "Numerical simulation on a pump operating in a turbine mode," in Proceedings of the Twenty-Third International Pump Users' Symposium, pp. 2175, Houston, Texas, USA, March 2007.

[25] P. Singh and F. Nestmann, "An optimisation routine on a prediction and selection model for the turbine operation of centrifugal pumps," Experimental Thermal and Fluid Science, vol. 12, 2010.

[26] C. Ren and J. Wang, "Routing optimisation for shared electric vehicles with ride-sharing," Complexity, vol. 2020, Article ID 9560135, 13 pages, 2020.

[27] H. Dang and Y. Du, "Synchronisation-Based GuaranteedPerformance Formation Design for Swarm Systems," Complexity, vol. 2020, Article ID 3076132, 13 pages, 2020.

[28] Y. Zhang, W. Fan, C. Xiang et al., "An innovative aerial manipulator with tandem ducted fans: modeling, control, and simulation," Complexity, vol. 2020, Article ID 7923539, 24 pages, 2020.

[29] C. S. Morros, J. M. F. Oro, and K. M. A. Diaz, "Numerical modelling and flow analysis of a centrifugal pump running as a turbine: unsteady flow structures and its effects on the global 
performance," International Journal of Numerical Methods Fluids, vol. 65, no. 5, pp. 542-562, 2011.

[30] D. Adu, J. Zhang, M. Jieyun, S. N. Asomani, and M. Osman, Numerical Investigation of Transient Vortices and Turbulent Flow Behaviour in Centrifugal Pump Operating in Reverse Mode as Turbine, Materials Science for Energy Technologies, Salt Lake City, UT, USA, 2018.

[31] Z. Jinfeng and A. Daniel, "Small hydropower by using pump as turbine for power generation in Southern Africa," Current Science, vol. 118, no. 3, 2020.

[32] C. Yun-Liang, C. Wu, Y. Mao et al., "Hydraulic characteristics of the vertical vortex at hydraulic intakes," Journal of Hydrodynamics, Ser B, vol. 19, no. 2, pp. 143-149, 2007.

[33] H. Che and Z. Bai, "A deep reinforcement learning approach to the optimisation of data center task scheduling," Complexity, vol. 2020, Article ID 3046769, 12 pages, 2020.

[34] L. V. Dai, N. M. Khoa, and L. C. Quyen, "An innovatory method based on continuation power flow to analyse power system voltage stability with distributed generation penetration," Complexity, vol. 2020, p. 15, Article ID 8037837, 2020.

[35] M. Yao, P. Liu, and H. Wang, "Nonlinear dynamics and power generation on a new bistable piezoelectric-electromagnetic energy harvester," Complexity, vol. 2020, Article ID 5681703, 29 pages, 2020.

[36] H. Yang, N. Shah, B. Nie et al., "Developing an efficient deep learning-based trusted model for pervasive computing using an LSTM-based classification model," Complexity, vol. 2020, Article ID 4579495, 6 pages, 2020.

[37] V. Thanh Pham, V. Sundarapandian, and K. Tomasz, "Complexity, dynamics, control, and applications of nonlinear systems with multistability," Complexity, vol. 2020, Article ID 8510930, 7 pages, 2020. 